\title{
ANÁLISE DA SATISFAÇÃO DOS FUNCIONÁRIOS COM AS MELHORIAS ERGONÔMICAS IMPLANTADAS NA DIVISÃO DE USINAGEM DA JOHN DEERE BRASIL
}

\section{EMPLOYEES SATISFACTION ANALYSIS WITH ERGONOMIC IMPROVEMENTS IMPLANTED IN JOHN DEERE BRAZIL MACHINING DEPARTAMENT}

\author{
Silvério Fonseca Kmita ${ }^{1}$; Lia Buarque de Macedo Guimarães ${ }^{2}$. \\ ${ }^{1}$ Universidade Federal do Rio Grande do Sul - UFRGS - Porto Alegre - Brasil \\ kmitasilveriof@johndeere.com \\ ${ }^{2}$ Universidade Federal do Rio Grande do Sul - UFRGS - Porto Alegre - Brasil \\ lia@producao.ufrgs.br
}

\begin{abstract}
Resumo
Este artigo faz parte da dissertação de mestrado do autor 1 e consiste no estudo das condições de trabalho e propostas de melhorias da Divisão de Usinagem da empresa John Deere, unidade Horizontina, RS. A Divisão é responsável pelo processamento de peças de aço e ferro fundido, componentes de plantadeiras, colheitadeiras e tratores. Utilizou-se a abordagem participativa da Análise Macroergonômica do Trabalho (AMT), proposta por Guimarães (1999) para identificação e priorização das demandas ergonômicas. Ao final de, aproximadamente 2 anos e meio, foram reavaliadas, por meio de um questionário, as modificações feitas no ambiente, em postos de trabalho e na organização do trabalho. De um modo geral, houve um aumento da satisfação dos funcionários evidenciando que é possivvel atender as exigências impostas por um mercado competitivo e globalizado sem que haja prejuizo aos fatores humanos envolvidos nesse processo de produção.
\end{abstract}

Palavras-chave: Macroergonomia, Usinagem; Validação Ergonômica.

\section{Introdução}

No passado, havia uma certa rigidez em relação à estrutura econômica e industrial. Os papéis dos fornecedores, fabricantes e distribuidores eram bem definidos, o que já não ocorre atualmente. Fenômenos como a globalização, rápida mudança tecnológica, evolução da internet, entre outros, trouxeram o abandono dos papéis formais, criando-se, assim, iniciativas de parcerias e soluções de continuidade que contribuíram para apagar os limites entre os papéis desempenhados pelas empresas (PRAHALAD E RAMASWAMY, 2000). Aperfeiçoar processos tornando-os mais 
eficazes, eficientes e adaptáveis, são questões relevantes em relação às perdas (HARRINGTON, 1988).

No entanto, salienta-se que essa modernização necessita ser feita de forma consciente e eficiente. Essas transformações, chamadas de reengenharia de negócios, exigem integração e compreensão de todos os envolvidos no processo, a fim de se buscar o chamado denominador comum, ou seja, ganhos oferecendo produtos e/ou serviços de qualidade. Durante a implementação de um programa de qualidade, deve-se buscar um equilíbrio entre as melhorias operacionais de produtividade e qualidade e os aspectos motivacionais e comportamentais, sem os quais não se sustenta um processo de melhorias contínuas (HARMON, 1993).

Sendo assim, este artigo consiste na identificação de elementos que interfiram nas condições de trabalho e sua conseqüente repercussão na satisfação dos trabalhadores. Faz-se um levantamento, análise e reformulação das condições de trabalho de uma Divisão de Usinagem (DIUS) da fábrica de máquinas agrícolas da John Deere Brasil, no Rio Grande do Sul e avalia-se o grau de satisfação dos operadores antes e após intervenção ergonômica. Utiliza-se o método da Análise Macroergonômica do Trabalho (AMT), proposta por Guimarães (1999). Essa abordagem macro, além de sua ênfase participativa, trás consigo outra importante característica, que é o desenvolvimento de suas etapas em integração com outros projetos participativos (tais como grupos de Círculo de Controle de Qualidade (CCQ’s), projeto Qualidade de Vida, etc.) que já estão sendo desenvolvidos pela empresa.

Em ergonomia, a forma de implantação de um Programa varia de acordo com as necessidades, interesses e possibilidades de cada empresa, sendo o enfoque macroergonômico um elo entre o desenvolvimento de um Programa e a implantação de uma cultura de ergonomia na empresa (GUIMARÃES, 2003).

Para a empresa, em estudo, o estabelecimento de um programa de ergonomia, com abordagem macroergonômica, criou mecanismos para sua difusão, fazendo com que seus conceitos sejam abordados em fases iniciais de desenvolvimento de projetos, usando a filosofia de prevenção e não de correção.

\section{Método de Desenvolvimento}

O método utilizado foi o da Análise Macroergonômica do Trabalho (AMT), proposta por Guimarães (1999). Seu desenvolvimento compreende as seguintes etapas: (lançamento do projeto, apreciação, diagnóstico, projetação e validação). 
A aplicação do AMT em empresas, parte do princípio que um Programa de Ergonomia deve identificar, monitorar e alterar quaisquer situações que comprometam a qualidade de vida no trabalho.

A AMT quando aplicada nas empresas, tem a orientação metodológica de uma pesquisaação, “... um tipo de pesquisa social com base empírica que é concebida e realizada em estreita associação com uma ação ou com a resolução de um problema coletivo e no qual os pesquisadores e os participantes representativos da situação ou do problema estão envolvidos de modo cooperativo ou participativo" conforme proposto por Thiollent (1994).

\subsection{Fatores Ergonômicos Considerados pelo AMT}

Quando da implementação de um programa continuado de ergonomia na empresa, segundo a AMT, essas categorias, são classificadas nos seguintes fatores, também chamados de construtos (GUIMARÃES, 2003).

Ambientais, Biomecânicos ou de Posto de trabalho, Cognitivos ou de Conteúdo, Organizacionais, de Risco e Empresa.

Salienta-se que o enquadramento do item de demanda ergonômica, em determinado construto, segundo o método AMT, é direcionado conforme relato do(s) func ionário(s), no momento da entrevista (fase de apreciação).

O construto “Ambiental” considera as questões do ambiente físico (ruído, vibrações, temperatura, iluminância e aerodispersóides) que geralmente impactam no trabalho (GUIMARÃES, 2003).

O construto "Biomecânicos" ou "Posto" (interface humano-máquina, consideram as questões biomecânicas (força, posturas adotadas) e fisiológicas (esforço físico, questões de higiene) envolvidas no trabalho. Basicamente, reflete as questões do espaço de trabalho, das condições do posto de trabalho, dos EPIs, uniformes e outros que podem ser consideradas como responsáveis pela carga física imposta, mas refletem, também, questões de ordem psicofísica. (GUIMARÃES, 2003).

O construto "Cognitivo" ou "de Conteúdo" considera a demanda mental, de processamento de informação, memória, atenção e tomada de decisão que é imposta para cumprimento da tarefa. É o que configura a percepção geral ou conteúdo de trabalho por parte do indivíduo (GUIMARÃES, 2003).

O construto "Organização do Trabalho" considera a forma de gestão do trabalho e as relações do trabalho na empresa, o que reflete no conteúdo do trabalho. A forma de gestão do trabalho compreende o ritmo de trabalho, forma de execução, as relações de poder, etc (GUIMARÃES, 2003). 
O construto "Risco" considera o grau de risco de um dado trabalho. Pode ser avaliado considerando o conteúdo das queixas médicas, dos motivos das CATs (Comunicação de acidente de trabalho) e de queixas junto ao setor de segurança da empresa (GUIMARÃES, 2003).

O último construto denomina-se "Empresa", que reflete a sua política interna e externa. A política interna destaca a forma como tratam seus funcionários, a quantidade e qualidade dos serviços de apoio para os funcionários. A política externa envolve toda a relação da empresa com programas com comunidade, bem como, a imagem da empresa na sociedade (GUIMARÃES, 2003).

Nesse estudo de caso os itens de demanda ergonômica foram classificados conforme os seguintes construtos:

“Ambientais": ruído, ruído de outros setores, temperatura, iluminação e contato com produtos químicos;

"Biomecânicos/Posto": Leiaute, espaço físico, manuseio de talhas e dispositivos, local para descanso, altura das mesas, banheiros, bebedouros, equipamentos de proteção e regulagem de máquinas;

Para todos os setores investigados, o construto "Organização do Trabalho" foi subdividido em dois:

“Organização do Trabalho" referente aos processos de trabalho, englobando questões envolvidas diretamente com a realização do trabalho. Foram considerados: ritmo de trabalho, o trabalho em si, informações técnicas, atendimento da manutenção;

“Organização do Trabalho" referente a relações do trabalho, com questões pertinentes às relações sociais. Foram considerados: relacionamento com colegas, relacionamento com a chefia, atendimento das necessidades, relação com o outro turno.

\section{A Divisão de Usinagem}

\subsection{Caracterização da Divisão de Usinagem}

Essa divisão é composta por 3 subdivisões de produção que são: Aços, Fundidos e Ferramentaria.

Estas três subdivisões normalmente atendem a demanda do setor de primários, aonde as matérias primas, que vêm dos estoques, ou de meio externo, como da fundição da John Deere, sofrem o primeiro processo de transformação na fabricação de componentes para colheitadeiras e tratores. A seguir, as peças processadas são encaminhadas a outros setores, principalmente para a pintura. Complementam a divisão de usinagem as áreas administrativas de Engenharia de Produção e Planejamento da Produção, que neste artigo não são focos de estudo. 
As tarefas da Divisão de Usinagem da John Deere, unidade Horizontina, são bem típicas: o processo mais comum, ou seja, o mais utilizado é o de furação. São utilizadas ferramentas como furadeiras manuais até centros de usinagem CNC. Outro processo que também é utilizado é o de fresamento.

Processos de retificas também são bem comuns dentro da divisão de usinagem, normalmente usado como processo de acabamento de peças que exigem uma tolerância muito pequena, ou seja, é uma operação que finaliza a peça e lhe dá o dimensionamento desejado.

Junto à subdivisão de Ferramentaria, desenvolvem-se trabalhos de suporte a outras subdivisões, como afiação de ferramentas que sofrem desgaste, principalmente brocas em processos de torneamento. Realiza-se, também, a fabricação de alguns componentes que servem de peças de reposição para aquelas que sofrem algum dano. Ainda dentro da ferramentaria, a tarefa de desenvolvimento de alguns dispositivos, projetados pela Engenharia de Produção desse setor, ocorre com freqüência: são feitos moldes que servem como padrão para a fabricação de outros componentes, dentro e fora da fábrica.

Os dois principais componentes trabalhados dentro da divisão de usinagem da John Deere são os aços e os ferros fundidos, sendo que os aços trazem em suas propriedades uma das principais características que dificultam o processamento: a dureza.

Um grande número de variáveis atua num processo de usinagem: além dos já citados como resistência dos materiais e movimentos de usinagem, ângulos de corte, controle da forma do cavaco, variações de força, pressão e potência de corte, fluidos de corte, entre outras, contribuem para a complexidade dos processos.

\subsection{Caracterização dos Funcionários da Divisão de Usinagem}

Para as três subdivisões, em relação ao sexo, todos são masculinos e a escolaridade varia de primeiro grau incompleto até terceiro completo. Tempo de serviço e idade estão caracterizados conforme Tabela 1:

Tabela 1 - Caracterização de idade e tempo de serviço

\begin{tabular}{|c|c|c|c|c|}
\hline \multicolumn{2}{|c|}{} & Mínimo & Máximo & Média \\
\hline \multirow{2}{*}{$\begin{array}{c}\text { Aço } \\
\text { diurno }\end{array}$} & Idade & 18 & 52 & 28,3 \\
\cline { 2 - 5 } $\begin{array}{c}\text { Aço } \\
\text { noturno }\end{array}$ & Tempo Serviço & 12 & 372 & 102,7 \\
\cline { 2 - 5 } & Tempo Serviço & 19 & 50 & 30,3 \\
\hline \multirow{2}{*}{$\begin{array}{c}\text { Ferramentaria } \\
\text { diurno }\end{array}$} & Idade & 16 & 341 & 119,5 \\
\cline { 2 - 5 } & Tempo Serviço & 24 & 216 & 25,5 \\
\hline
\end{tabular}




\begin{tabular}{|c|c|c|c|c|}
\hline \multirow{2}{*}{$\begin{array}{c}\text { Ferramentaria } \\
\text { noturno }\end{array}$} & Idade & 21 & 47 & 31,3 \\
\cline { 2 - 5 } & Tempo Serviço & 60 & 324 & 169,5 \\
\hline \multirow{2}{*}{$\begin{array}{c}\text { Fundidos } \\
\text { diurno }\end{array}$} & Idade & 16 & 48 & 28,4 \\
\cline { 2 - 5 } $\begin{array}{c}\text { Fundidos } \\
\text { noturno }\end{array}$ & Tempo Serviço & 12 & 436 & 117,2 \\
\cline { 2 - 5 } & Tempo Serviço & 24 & 336 & 29,1 \\
\hline
\end{tabular}

Fonte: JOHN DEERE, 2003.

\section{Implementação das Melhorias}

Criou-se uma planilha, chamada de plano de ação, que continha os seguintes tópicos: $\mathrm{O}$ QUE?, identificando o problema, QUEM?, colocando um responsável direto para atuar sobre o problema, QUANDO?, estimando uma data para a resolução do problema, ONDE?, localizando o problema dentro do setor, POR QUE?, justificando a possível alteração e mostrando o seu benefício, COMO?, avaliando e mostrando como agir, além de mostrar seu efeito no âmbito geral do setor e finalmente criando o tópico STATUS, que localizava o andamento das modificações, para que todos soubessem se estava em andamento, em que fase estaria ou se já estivesse concluído.

\subsection{Melhorias Físico-Ambientais}

Quanto aos fatores físico-ambientais, foram realizadas ações que partiram de simples orientações, focadas na conscientização dos funcionários em relação a determinados problemas, até modificação ou eliminação de dispositivos e máquinas.

Buscou-se evidenciar, através de reuniões, os problemas com perdas auditivas. Os operadores foram orientados a respeito do uso correto de protetores auriculares, reforçando-lhes as conseqüências do uso incorreto ou do não uso. Também foram orientados para que algumas máquinas fossem desligadas, quando isso fosse possível, entre uma operação e outra.

Junto com o setor de Segurança e Medicina do Trabalho, mapeou-se as máquinas que apresentavam um nível de pressão sonora fora do recomendado.

Junto com os grupos de CCQ's, que já vinham trabalhando em projetos que visavam a minimização de ruídos, conseguiu-se projetar e aplicar uma cabine acústica nos motores e sistemas de refrigeração. Trabalhou-se em conjunto com a manutenção, trocando-se rolamentos de motor e buchas diminuindo o ruído em cilindro. Outro fator que agravava o ruído no setor era os esmeris, seus motores e revestimentos elevavam o problema. Foi criada uma central de rebarbações de peças com esmeris pneumáticos, onde se aproveitou a ocasião para fazer uma revisão nas mangueiras de ar comprimido, colocando um manômetro para fazer a regulagem da pressão. O revestimento de 
alguns dispositivos com borrachas, evitando contato de metal com metal, foi outra medida que também converteu em ótimos resultados.

Medidas quanto à iluminação nos postos de trabalho também foram analisadas. Os dados que a empresa possuía, somados a novas avaliações, constataram que alguns postos de trabalho mereciam uma atenção especial.

Devido ao fato de algumas operações em processos de usinagem exigirem alto grau de acabamento, dentro de padrões de tolerâncias muito pequenos, e por tanto as atividades realizadas junto à máquina exigir muita atenção, com perfeita visualização, evidenciou-se a necessidade da colocação ou substituição de algumas lâmpadas para atender a essas necessidades. Tomou-se o cuidado para que durante a reposição, ajuste ou colocação dessas lâmpadas, junto ao centro de usinagem, o operador tivesse boas condições de visualização e ao mesmo tempo tendo o cuidado de não lhe causar o ofuscamento.

Quanto à utilização de produtos químicos, trabalhou-se na minimização do contato do operador com o fluído lubrificante dos centros de usinagem. Foram colocados anteparos nas máquinas, evitando maiores respingos, corrigiu-se os vazamentos das máquinas, evitando escoamento pelo piso, trocaram-se óleos lubrificantes químicos por outros de composição mais natural e menos danoso a saúde e foram facilitadas trocas de EPI's.

O processo de revisão e mapeamento das condições das máquinas foi feito em todos as subdivisões da usinagem, bem como em outras Divisões o que também atendeu a outro item de demanda ergonômica levantado pelos funcionários: "ruído proveniente de outros setores".

Em relação à temperatura no ambiente de trabalho, foram colocados ventiladores em locais estratégicos. Essa é uma medida intermediária, pois há projetos de ventilação natural ou forçada para toda fábrica, que demandam maior investigação, pois o custo é elevado, requerendo maior tempo para tomada de decisão.

\subsection{Melhorias nos Postos de Trabalho}

Em relação ao construto "Biomecânico/Posto", a compra de talhas e dispositivos para manuseio de matéria prima foi uma das primeiras ações. O levantamento e carregamento de peças que exigiam grande esforço físico se davam diariamente em determinados postos de trabalho.

As prateleiras foram organizadas e a colocação de roletes para tirar a peça da estante somado à colocação de talhas, ajudou a diminuir, ainda mais, o manuseio de peso. Orientou-se para que as peças mais pesadas ficassem sempre nas prateleiras do meio ou embaixo, deixando as de cima para peças e dispositivos mais leves e usuais. 
Foram tomadas medidas quanto à segurança dos funcionários, sendo assim, máquinas que apresentavam riscos ao operador durante o processo de usinagem sofreram modificações. Elementos móveis das máquinas que poderiam trazer algum risco ao operador foram isolados.

Optou-se pelo enclausuramento total das máquinas de usinagem, evitando o contato direto do operador com ferramentas pontiagudas e ou em movimento. Esse isolame nto deve proteger também o operador do contato direto com cavacos e fluido refrigerante durante a operação da máquina. A parte elétrica foi isolada, evitando riscos de choques. $\mathrm{O}$ enclusuramento das máquinas do centro de usinagem colaborou, também, para a redução nos níveis de pressão sonora, conforme já comentado.

Novos centros de usinagem foram adquiridos, fazendo com que um único centro realizasse várias operações. Isso abriu caminho para melhorias no leiaute da divisão. Máquinas foram agrupadas seguindo o fluxo de produção o que diminuiu transportes de peças e criou mais espaços. Atuou-se fortemente na questão organizacional da divisão, demarcando locais específicos para os dispositivos e acessórios de auxílio à produção.

Orientou-se também para obtenção de melhor organização e centralização do material de limpeza, que ficava espalhado pela fábrica. Para isso, foi criada uma central com todos os materiais de limpeza necessários.

As queixas referentes a "banheiro" diziam respeito às privadas. Usavam-se somente as chamadas "bacias turcas" e não havia vasos sanitários. Optou-se por disponibilizar vasos para os banheiros, deixando algumas "bacias turcas", pois alguns funcionários alegavam gostar das mesmas devido à higiene.

A queixa em relação à "qualidade da água" foi registrada em toda a fábrica, não sendo específica dessa divisão. No entanto, os índices de insatisfação dos questionários contribuíram, com dados quantitativos, para uma mudança geral. Foram trocados todos os filtros dos bebedouros, bem como suas encanações.

Salienta-se que foi criada a figura dos facilitadores, funcionários responsáveis pela organização de determinados postos (banheiros, central de ferramentas, central de limpeza, etc.), o que ajudou a manter a parte organizacional, conforme planejamento inicial.

\subsection{Melhorias de Organização do Trabalho}

Com relação à "necessidade de maior número de funcionários" na divisão, principalmente no turno da noite, a medida foi atuar na organização e conteúdo do trabalho. Os funcionários foram incentivados a desenvolver a multifuncionalidade em diferentes postos de trabalho. A ênfase foi dada buscando-se o enriquecimento do trabalho (agrupamento de atividades com diferentes fontes 
de processamento ou teor cognitivo), ao invés do simples alargamento (agrupamento de atividades de mesmo teor).

\section{Validação}

Desde o lançamento do Programa de Ergonomia na John Deere, utilizando a AMT, passando pela etapa de apreciação com as entrevistas, estruturação e aplicação dos primeiros questionários, tabulação de dados, divulgação dos resultados (retorno aos funcionários), passaram-se aproximadamente três meses. As aplicações das primeiras medidas corretivas foram logo colocadas em ação, porque muitos dos itens levantados já vinham sendo estudados pelos grupos de ciclos de controle de qualidade (CCQ's) ou eram de fácil resolução.

Outras transformações, classificadas como de médio ou alto grau de dificuldades de implementação, foram sendo estudadas e desenvolvidas dentro de espaços de tempo bastante diferentes. Muitas dessas melhorias necessitavam, obrigatoriamente, passar por um estudo financeiro mais detalhado, visto que a John Deere trabalha com um sistema de custeio chamado "centro de custos" e faz seu planejamento de investimentos anualmente. Sendo assim, a aplicação do segundo questionário deu-se aproximadamente dois anos e meio após o primeiro.

A fim de buscar mensurar a satisfação dos funcionários, em relação às modificações implementadas, um segundo questionário foi elaborado. Optou-se pela aplicação de um questionário com questões idênticas ao primeiro (Validação).

\section{Análise dos Dados}

A aplicação da estatística junto a empresas é um importante fator na tomada de decisões, auxiliando na tríplice função dos seus administradores, que são de organizar, dirigir e controlar a empresa (CRESPO, 1996).

Para esse artigo, onde foram investigadas subdivisões (Aço, Ferramentaria e Fundidos), optou-se, inicialmente, pela representação gráfica com comportamento de médias obtidas, pois o mesmo auxilia a visualizar e compreender melhor o fenômeno em estudo.

\subsection{Análise inicial dos dados dos questionários}

A Figura 1 mostra a diferença entre as respostas médias obtidas antes da intervenção ergonômica e depois. Nota-se que para o momento 1 (antes da intervenção) a média das respostas é menor do que para o momento 2 (após intervenção) indicando um resultado positivo para o trabalho desenvolvido. 
Figura 1 - Média geral dos momentos

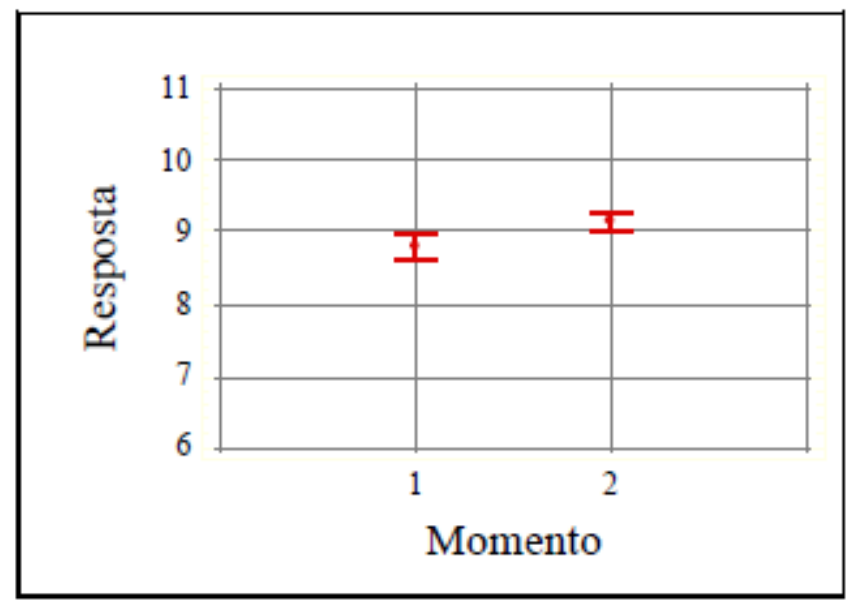

Fonte: JOHN DEERE, 2003

\subsection{Análise de Variância (ANOVA)}

A fim de assegurar o respaldo científico às conclusões e pela necessidade de comparação dos dados pesquisados, foi utilizado o teste estatístico de análise de variância (ANOVA). Tal análise determinará se existem diferenças significativas entre os grupos e, se existir, quais grupos são significativamente diferentes um do outro.

A necessidade da análise de interações, por exemplo setor $\mathrm{x}$ turno, fez com que fosse utilizado a ANOVA univariate, onde se faz a análise de uma variável dependente por mais de um fator e/ou variáveis. A contribuição de cada fator é medida removendo os efeitos de todos os fatores restantes. Testa-se o significado estatístico de cada um dos fatores (SIG). Desde que, "SIG." Seja menor de 0.05 , estes fatores têm efeito estatístico significativo, com intervalo de confiança de $95 \%$.

Para uma análise mais aprofundada, envolvendo os setores analisados e as variáveis, turnos, momentos e construtos, faz-se uso da Anova Univariate. Verifica-se a significância dos fatores, bem como as interações de dois fatores que se mostram significativas.

A Tabela 2 apresenta a análise de variância envolvendo as subdivisões, Aços, Fundidos e Ferramentaria. 


\begin{tabular}{|c|c|c|c|c|c|}
\hline Causas de Variação & Soma de Quadrados & GL & Quadrado Médio & $\mathbf{F}$ & SIG. \\
\hline \multicolumn{6}{|l|}{ Efeito principal } \\
\hline A: Setor & 46,8179 & 2 & 23,4089 & 5,70 & 0,0035 \\
\hline B: Turno & 55,1388 & 1 & 55,1388 & 13,43 & 0,0003 \\
\hline C: Momento & 19,2914 & 1 & 19,2914 & 4,70 & 0,0304 \\
\hline D:Construto & 990,026 & 3 & 330,009 & 80,41 & 0,0000 \\
\hline \multicolumn{6}{|l|}{ INTERAÇOES } \\
\hline $\mathrm{AB}$ & 64,9678 & 2 & 32,4839 & 7,91 & 0,0004 \\
\hline $\mathrm{AC}$ & 47,6819 & 2 & 23,8409 & 5,81 & 0,0031 \\
\hline $\mathrm{AD}$ & 65,8179 & 6 & 10,9697 & 2,67 & 0,0141 \\
\hline $\mathrm{BC}$ & 1,92183 & 1 & 1,92183 & 0,47 & 0,4940 \\
\hline BD & 18,5589 & 3 & 6,1863 & 1,51 & 0,2111 \\
\hline$C D$ & 30,2239 & 3 & 10,0746 & 2,45 & 0,0619 \\
\hline $\mathrm{ABC}$ & 39,7249 & 2 & 19,8624 & 4,84 & 0,0081 \\
\hline$A B D$ & 13,1788 & 6 & 2,19647 & 0,54 & 0,7817 \\
\hline$A C D$ & 48,925 & 6 & 8,15416 & 1,99 & 0,0650 \\
\hline$B C D$ & 3,35001 & 3 & 1,11667 & 0,27 & 0,8456 \\
\hline$A B C D$ & 18,8738 & 6 & 3,14564 & 0,77 & 0,5964 \\
\hline Resíduo & 3611,7 & 880 & 4,1042 & & \\
\hline TOTAL CORRIGIDO & 5550,79 & 927 & & & \\
\hline
\end{tabular}

Como pode ser visto, todos os fatores principais são significativos. O efeito mais forte é, de longe, $\mathrm{o}$ efeito do construto, $\mathrm{F}=80,41 ;$ e $\mathrm{SIG} .=0,000 \quad(\mathrm{p}<0,000)$, seguido de turno $(\mathrm{F}=13,43 ; \mathrm{p}=0,0003)$, setor $(\mathrm{F}=5,70 ; \mathrm{p}=0,0035)$ e depois, momento $(\mathrm{F}=4,70 ; \mathrm{p}=0,0304)$. Também há interações de dois e três fatores que são significativas. A seguir, apresentam-se os gráficos das interações "Construto x Setor" e "Momento x Setor", interações de dois fatores (que revelaram significância) e que são importantes para uma análise mais detalhada.

Conforme Figura 2, tem-se a interação dos construtos com os setores. Nota-se que, para todos os setores, o construto ambiental possui as menores médias de satisfação, sendo que o setor de Fundidos apresenta os menores valores, com média inferior a 7. No outro extremo, tem-se a "Organização", "relações do trabalho" com as maiores médias de satisfação, em todos os três setores analisados.

O construto "Biomecânico/Posto", junto ao setor de Aço possui média superior a 8, mas no setor de Fundidos, a média cai significativamente, tornando a subir no setor de Ferramentaria, superando Aços, com média próxima de 9. O setor de Fundidos tem as menores médias, na 
interação com os construtos "Ambientais", "Biomecânico/Posto" e "Organização" "relações de trabalho". A exceção está na "Organização" "processos de trabalho", onde o setor de Aço possui a menor média, no outro extremo encontra-se a Ferramentaria com média num valor acima de 10.

Figura 1: Cruzamento dos fatores Construto X Setores

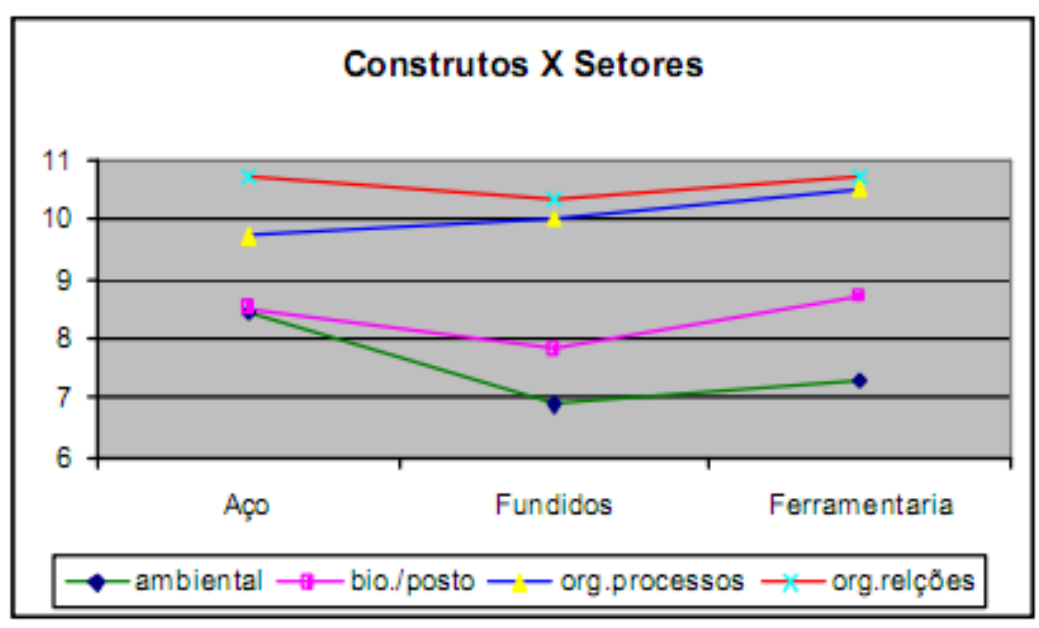

Fonte: JOHN DEERE, 2003

Figura 2: Cruzamento dos fatores Momento X Setores

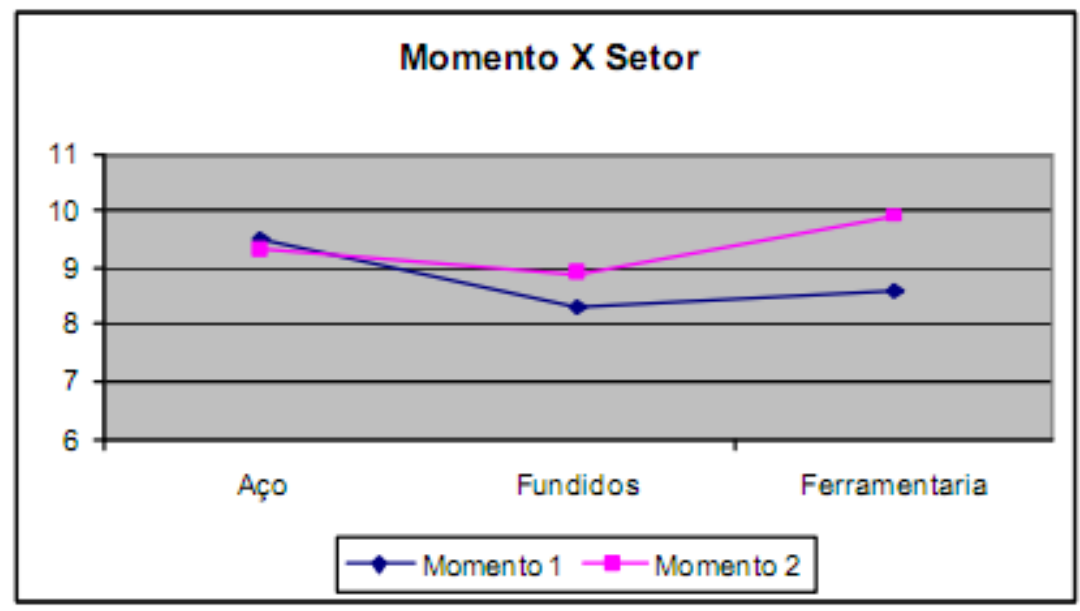

Fonte: JOHN DEERE, 2003

$\mathrm{Na}$ interação momento x setor (Figura 3), nota-se que o setor de Aço possui média de satisfação, antes da intervenção ergonômica, maior do que após a intervenção. Já nos outros setores, Fundidos e Ferramentaria, essa ordem sofre uma inversão, ou seja, após a intervenção, os valores médios de satisfação aumentam. A maior diferença é encontrada no setor de Ferramentaria.

Buscou-se averiguar essa inversão de expectativa, em relação a subdivisão de aço (momento1 maior que momento 2), ou seja, satisfação antes da intervenção maior que após a intervenção. Notou-se que situações que eram rotineiras e que talvez passassem desapercebidas, após discernimento do problema, conhecimento de uma relação "trabalho em determinado posto $\mathrm{x}$ 
alguma distúrbio", quando do momento de alguma reavaliação, são passíveis de notas mais críticas.

É o caso da subdivisão de Aços, que no Construto ambiental, para os cinco itens analisados nesse construto, 4 obtiveram melhorias na média de satisfação, mas 1 item (temperatura no ambiente de trabalho) obteve notas, muito mais baixas, tanto o diurno quanto o noturno, mesmo após melhorias intermediárias (colocação de ventiladores). Esse único fator inverteu a expectativa inicial. O uso de alternativas intermediárias colaborou para com o despertar do senso crítico de alguns funcionários, rapidamente difundido entre outros.

\title{
7. Conclusões
}

Os trabalhadores da Divisão de Usinagem consideraram o processo de mudança, participativo, importante para a melhoria das condições de trabalho, repercutindo no aumento de satisfação.

Boas condições de posto de trabalho somado à boa organização do trabalho são condições iniciais para atuar-se em questões de conteúdo do trabalho. O método da Análise Macroergonômica do Trabalho (AMT) é uma ferramenta que auxilia nessa busca, não confrontando com trabalhos que já vem sendo desenvolvidos nas empresas, isso faz com que ele siga as tendências do futuro que é a unificação (padronização) de programas.

A desenvoltura desses trabalhos está diretamente ligada a abertura da empresa na busca de uma filosofia conciliadora entre fatores humanos e produtivos. O método participativo foi gradualmente sendo incorporado e divulgado pelas Divisões da empresa, mesmo aqueles gerentes que possuem característica conservadora, ou seja, pouco favoráveis a mudanças, aos poucos foram sendo capacitados e acabaram sendo vetores para a divulgação do método, esse fato foi fundamental para o bom andamento do projeto e as conseqüentes melhorias obtidas.

\begin{abstract}
This article makes part of the Master Degree dissertation of the author ${ }^{1}$ and consists in the study of work conditions and improvements proposals for John Deere Machining Department from Horizontina unit in RS. This Department is responsible for steel parts processing and casting iron, planters, combines and tractors components. It was used participative method, Macroergonomics Work Analysis (AMT), by Guimarães (1999) to identify and give priority to ergonomic demands. Before, 2 years and a half approximately, the alterations made in the environment, workplaces and in work organization were reevaluated by questionnaire. In general, it had an employees satisfaction increase, demonstrating that it's possible to attend the requirements imposed by a competitive and globalize market without human factors damage involved in this production process.
\end{abstract}

Key-words: Macroergonomics; Machining; Ergonomic Validation.

\section{Referências}

CRESPO, A. A., Estatística fácil. São Paulo, ed. Saraiva, 1996. 
GUIMARÃES, L. B. de M. Abordagem ergonômica: o método macro. In: Guimarães. Ergonomia de Processo. 1. ed. [Porto Alegre: UFRGS/PPGEP, 1999]. cap. 1.1. v. 1.

GUIMARÃES, L. B. de M. Análise Macroergonômica do Trabalho (AMT): modelo de implementação e avaliação de um programa de ergonomia na empresa. Material submetido à revista Produto \& Produção, 2003.

HARMON, Roy L. Reinventando a fabrica II,. Rio de Janeiro: Campus, 496p., 1993.

HARRINGTON, H. J. O processo do aperfeiçoamento. São Paulo: Mcgraw-Hill do Brasil, 266 p., 1988.

PRAHALAD C. K. e RAMASWAMY, V. Como incorporar as competências do cliente. Revista HSM Management, número 20, ano 4, maio-junho, 2000.

THIOLLENT, M.,J. Metodologia da pesquisa-ação. São Paulo: Cortez, 108 p.,2000

\section{Dados completos do primeiro autor:}

Nome completo: Silvério Fonseca Kmita

Filiação institucional: Universidade Federal do Rio Grande do Sul

Endereço completo para correspondência (bairro, cidade, estado, país e CEP):

Rua 3 de Maio, 156/302 - Horizontina - RS- Cep: 98920-000

Telefones para contato: (55) 35373741

e-mail: kmitasilveriof@johndeere.com

Recebido para publicação em: 01/12/2005

Aceito para publicação em: 27/02/2006 